\title{
Inhibition of Rho via Arg and p190RhoGAP in the Postnatal Mouse Hippocampus Regulates Dendritic Spine Maturation, Synapse and Dendrite Stability, and Behavior
}

\author{
Mindan K. Sfakianos, ${ }^{1}$ Aaron Eisman, ${ }^{1 *}$ Shannon L. Gourley, ${ }^{2,3 *}$ William D. Bradley, ${ }^{1 *}$ Alfred J. Scheetz, ${ }^{1}$ \\ Jeffrey Settleman, ${ }^{6}$ Jane R. Taylor, ${ }^{2,3}$ Charles A. Greer, ${ }^{2,4,5}$ Anne Williamson, ${ }^{4}$ and Anthony J. Koleske ${ }^{1,2,5}$ \\ ${ }^{1}$ Department of Molecular Biophysics and Biochemistry, ${ }^{2}$ Interdepartmental Neuroscience Program, and Departments of ${ }^{3}$ Psychiatry, ${ }^{4}$ Neurosurgery, and \\ ${ }^{5}$ Neurobiology, Connecticut Mental Health Center, Yale University School of Medicine, New Haven, Connecticut 06520, and ${ }^{6}$ Massachusetts General \\ Hospital Cancer Center, Harvard Medical School, Charlestown, Massachusetts 02129
}

The RhoA (Rho) GTPase is a master regulator of dendrite morphogenesis. Rho activation in developing neurons slows dendrite branch dynamics, yielding smaller, less branched dendrite arbors. Constitutive activation of Rho in mature neurons causes dendritic spine loss and dendritic regression, indicating that Rho can affect dendritic structure and function even after dendrites have developed. However, it is unclear whether and how endogenous Rho modulates dendrite and synapse morphology after dendrite arbor development has occurred. We demonstrate that a Rho inhibitory pathway involving the Arg tyrosine kinase and p190RhoGAP is essential for synapse and dendrite stability during late postnatal development. Hippocampal CA1 pyramidal dendrites develop normally in $\mathrm{arg}^{-/}$mice, reaching their mature size by postnatal day 21 (P21). However, dendritic spines do not undergo the normal morphological maturation in these mice, leading to a loss of hippocampal synapses and dendritic branches by P42. Coincident with this synapse and dendrite loss, $\mathrm{arg}^{-/-}$ mice exhibit progressive deficits in a hippocampus-dependent object recognition behavioral task. p190RhoGAP localizes to dendritic spines, and its activity is reduced in $\mathrm{arg}^{-/-}$hippocampus, leading to increased Rho activity. Although mutations in p190rhogap enhance dendritic regression resulting from decreased Arg levels, reducing gene dosage of the Rho effector ROCKII can suppress the dendritic regression observed in $\mathrm{arg}^{-/-}$mice. Together, these data indicate that signaling through Arg and p190RhoGAP acts late during synaptic refinement to promote dendritic spine maturation and synapse/dendrite stability by attenuating synaptic Rho activity.

Key words: Arg tyrosine kinase; dendrite; synapse; hippocampus; p190RhoGAP; Rho

\section{Introduction}

The ability of a neuron to integrate into networks and process information is determined by the size and shape of its dendrite arbor. Dendrite arbor growth in the CNS is choreographed by a diverse set of cues. These cues regulate the activity of Rho family GTPases RhoA, Rac1, and Cdc42, which coordinate the actin cytoskeletal rearrangements required for dendrite morphogenesis (Luo, 2002; Van Aelst and Cline, 2004; Govek et al., 2005). In neurons, RhoA (Rho) acts via its neuronal effector Rho kinase (p160ROCK/ROCKII) (Hirose et al., 1998) to regulate actin po-

\footnotetext{
Received Feb. 21, 2007; revised Aug. 24, 2007; accepted Aug. 25, 2007.

This work was supported by United States Public Health Service Grants NS39475 and MH77306 (A.J.K.), by grants from the National Institutes of Health-National Institute on Deafness and Other Communication Disorders (C.A.G.) and the National Alliance for Research on Schizophrenia and Depression, by a Leslie J. Warner Postdoctoral Fellowship (M.K.S.), and by a National Research Service Award (NS058086) Predoctoral Fellowship (W.D.B.). We are grateful to Dr. David Wells for help on synaptoneurosome isolation; to Christine Kaliszewski, Youlan Lee, and Xianyun Ye for expert technical assistance; to Eva Moresco for logistical support; and to Ruth Koleske for statistical analysis. We thank Shuh Narumiya for sharing the rockll mice.

*A.E., S.L.G., and W.D.B. each made substantial contributions.

Correspondence should be addressed to Dr. Anthony J. Koleske, Department of Molecular Biophysics and Biochemistry, 333 Cedar Street SHMC-E31, Yale University School of Medicine, New Haven, CT 06520. E-mail: anthony.koleske@yale.edu.

DOl:10.1523/JNEUROSCI.0793-07.2007

Copyright $\odot 2007$ Society for Neuroscience $\quad$ 0270-6474/07/2710982-11 $\$ 15.00 / 0$
}

lymerization (Da Silva et al., 2003) and actomyosin contractility (Ridley, 2001). Rho activation in developing neurons reduces dendrite branch dynamics (Li et al., 2000, 2002), resulting in dendrite arbors with reduced complexity (Ruchhoeft et al., 1999; Lee et al., 2000; Govek et al., 2004). Expression of constitutively active Rho in mature neurons leads to dendritic spine loss and dendritic regression (Nakayama et al., 2000; Tashiro et al., 2000; Govek et al., 2004), but it is unclear whether and how endogenous Rho regulates dendritic spine maturation and dendrite arbor stability in late postnatal development.

The Abl family nonreceptor tyrosine kinases Abl and Arg act downstream of adhesion receptors to mediate changes in neuronal morphogenesis (Wills et al., 1999; Zukerberg et al., 2000; Woodring et al., 2002; Hernandez et al., 2004; Moresco et al., 2005; Thompson and Van Vactor, 2006). Arg is required for cortical dendrite branch maintenance in the postnatal mouse brain (Moresco et al., 2005), but the cellular and molecular mechanisms by which Arg promotes dendrite stability are unclear. We have recently shown that Arg acts via its substrate p190RhoGAP to inhibit Rho after fibroblast adhesion to fibronectin (Hernandez et al., 2004; Bradley et al., 2006; Peacock et al., 2007). Arg, p190RhoGAP, and Rho are all enriched in dendritic spines (Lamprecht et al., 2002; Moresco et al., 2003; Santos Da Silva et al., 
2004). These observations suggest that Arg/p190RhoGAP signaling may act in dendritic spines to influence the stability of dendritic arbors.

We provide evidence here that Arg signaling through p190RhoGAP promotes hippocampal dendrite arbor stability by regulating dendritic spine morphology. Dendrite arbors on hippocampal CA1 pyramidal neurons reach their normal mature size in $\mathrm{arg}^{-/-}$mice by postnatal day 21 (P21) but are not maintained, leading to dendrite regression by $\mathrm{P} 42$. The loss of dendrite branches in $\mathrm{arg}^{-/-}$mice is accompanied by a reduction in hippocampal synapses and poor performance in a hippocampusdependent behavioral test. In wild-type (WT) mice, dendritic spines transition from a larger size and broader distribution of morphologies at P21 to a smaller, more homogeneous morphology by early adulthood, but this morphological transition is not observed in $\mathrm{arg}^{-1-}$ mice. p190RhoGAP activity is reduced in $\mathrm{arg}^{-/-}$hippocampi, resulting in increased Rho activity. Importantly, genetic experiments indicate that p190rhogap mutations enhance the effects of $\arg$ mutations on apical dendrite arbors, whereas rockII mutations suppress the dendritic instability observed in $\mathrm{arg}^{-/-}$mice. Together, these data indicate that Arg signaling through p190RhoGAP promotes hippocampal synapse and dendrite stability by regulating Rho activity in the dendritic spine.

\section{Materials and Methods}

Biocytin injection of hippocampal neurons. Hippocampal slices $(400 \mu \mathrm{m})$ were prepared and maintained in a standard interface chamber at $33^{\circ} \mathrm{C}$. Individual CA1 pyramidal neurons were injected with $4 \%$ biocytin solution in $2 \mathrm{M}$ sodium acetate solution, $\mathrm{pH}$ 7.5. Neurons were injected with $100 \mathrm{~ms}$ current injections of $5 \mathrm{nA}$ at $1 \mathrm{~Hz}$ for $10 \mathrm{~min}$. After $10 \mathrm{~min}$ of recovery, injected neurons were fixed in $4 \%$ paraformaldehyde overnight, cryoprotected in 30\% sucrose, resectioned at $40 \mu \mathrm{m}$, and visualized using standard avidin-horseradish peroxidase (HRP) staining (Vectastain Elite ABC; Vector Laboratories, Burlingame, CA).

Morphometric analysis of neurons. Individual biocytin-labeled neurons were traced under $100 \times$ magnification using a light microscope outfitted with a $\mathrm{Z}$ drive and reconstructed using Neurolucida software (MicroBrightField, Williston, VT). Sholl analysis, total dendrite length, and branchpoint number were determined using NeuroExplorer software (MicroBrightField). Neurons were traced by an experimenter blind to the genotype.

Electron microscopy. Mice were perfused transcardially under deep anesthesia with halothane inhalation. A short perfusion with $0.1 \mathrm{M} \mathrm{PBS,} \mathrm{pH}$ 7.4 , was followed by a perfusion with $4 \%$ paraformaldehyde $/ 0.2 \%$ glutaraldehyde in $0.1 \mathrm{~m}$ PBS, pH 7.4. Brains were dissected and postfixed in the same solution overnight at $4^{\circ} \mathrm{C}$. Vibratome sections of the hippocampus were cut and processed in $1 \% \mathrm{OsO}_{4}$ at $4^{\circ} \mathrm{C}$ for $1 \mathrm{~h}$ (Schikorski and Stevens, 1997). After dehydration in ethanol, the sections were contrasted en bloc in $0.5 \%$ uranyl acetate in $95 \%$ ethanol for $1 \mathrm{~h}$ and flatembedded in Epon. Embedded vibratome sections were further cut to 70 $\mathrm{nm}$ thickness for electron microscopy. Synapses were photographed with a Jeol (Peabody, MA) 100 CX II electron microscope.

Immunolocalization of p190RhoGAP was performed as described previously (Moresco et al., 2003). Mice were killed and perfused as above, and brains were excised and postfixed with $0.1 \mathrm{~m}$ borate buffer, $\mathrm{pH}$ 10.4, $4 \%$ paraformaldehye overnight at $4^{\circ} \mathrm{C}$. Coronal sections $(1-5 \mathrm{~mm})$ of the hippocampus were cut and treated with $1 \%$ sodium borohydride for 45 min. Sections were rinsed repeatedly and cryoprotected in $20 \%$ glycerol and $15 \%$ sucrose. Sections were frozen on powdered dry ice. Samples were thawed, and 60 - to $100-\mu \mathrm{m}$-thick sections were cut using a vibratome. Sections were treated with $10 \%$ normal serum in PBS for $1 \mathrm{~h}$, followed by incubation in a 1:500 dilution of anti-p190RhoGAP antibodies (Becton Dickinson, San Jose, CA). Antibody/antigen interaction was detected by avidin/biotin complex coupled to HRP according to the manufacturer's instructions (Vector Laboratories). Sections were pro- cessed for conventional electron microscopy. Contrast was enhanced by the application of $1 \%$ lead acetate.

Morphometric analysis of synapses. The electron micrographs were obtained at a magnification of $12,000 \times$ or $25,000 \times$ and scanned at 12,000 dpi resolution. Excitatory synapses were identified in electron micrographs as mushroom-shaped spines containing a postsynaptic density (PSD) apposed to a presynaptic terminus with associated synaptic vesicles according to previously described criteria (Harris et al., 1992; Schikorski and Stevens, 1997). PSD length and dendritic spine area was determined using NIH ImageJ software. Spine area was traced from the thinnest part of the neck. All measurements were made by an experimenter blinded to the sample identity.

Analysis of dendritic spines. Brains from WT and $\mathrm{arg}^{-/-}$mice expressing the GFP-M1 transgene (Feng et al., 2000) were fixed by transcardial perfusion, and $20 \mu \mathrm{m}$ sections were imaged on a Leica (Nussloch, Germany) confocal microscope. Protrusions and spines were enumerated and measured using ImageJ software. All analyses were performed blinded to the genotype of the samples.

Immunoblotting. Tissue samples were disrupted in $50 \mathrm{~mm}$ Tris, $\mathrm{pH} 6.8$, $10 \%$ glycerol, $2 \%$ SDS, and 1\% 2-mercaptoethanol and boiled for 10 $\mathrm{min}$, and the protein concentration was determined using the bicinchronic acid assay (BCA; Pierce, Rockford, IL). Extracts were separated on 8\% SDS-PAGE gels, blotted to nitrocellulose membrane, and probed with anti-Abl (PharMingen, San Diego, CA) or anti-Arg (Koleske et al., 1998) antibodies.

Object recognition task. Locomotor activity during an initial $30 \mathrm{~min}$ habituation phase was monitored with the automated Omnitech (Columbus, $\mathrm{OH}$ ) Digiscan Micromonitor system equipped with 16 photocells and the same type of cages normally used to house rats $(45 \times 24 \times$ $20 \mathrm{~cm}$ ). Object recognition tests were conducted in a lit, quiet room using 12- to 16-week-old male WT, $a b l^{-\prime-}$, $\mathrm{arg}^{-/-}$, or $a b l^{-1-} \mathrm{arg}^{-/-}$double-

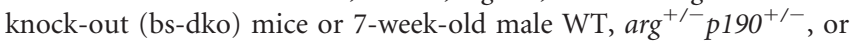
$\mathrm{arg}^{-1-} \mathrm{rock}^{+/-}$mice using an adaptation of a previously described protocol (Gresack and Frick, 2003).

After habituation, mice were briefly removed and placed in the home cage while two identical objects ( $15 \mathrm{ml}$ Falcon tubes) were placed at opposite ends of the cage. For both the sample and choice phases, mice were allowed to explore the objects for a total of $30 \mathrm{~s}$ before removal from the cage. Mice that did not explore the objects for a total of $30 \mathrm{~s}$ within $3 \mathrm{~m}$ were excluded from additional testing. Forty-eight hours after the sample phase, the choice test was performed in which the familiar object and a novel object (wrapped $1 \mathrm{ml}$ syringe barrel) were placed at opposite ends of the same cage the mouse had previously explored. The location of the novel object was counterbalanced across mice in each group. Exploration of the objects was videotaped with a camera suspended above the cage. Exploration was defined as nasal or oral contact with the objects, and a single blinded rater scored all sessions. Exploration time of the familiar objects in the sample and choice phase was analyzed by two-factor (genotype vs location) repeated-measures (RM)-ANOVA to verify the absence of side preferences that could bias performance in the choice phase. Exploration of the novel object was analyzed by two-factor (genotype vs location) RM-ANOVA. Data collected from WT, $\mathrm{arg}^{+/-} \mathrm{p190}+$, and $\mathrm{arg}^{-/-} \mathrm{rock}^{+/-}$mice were further interrogated by within-genotypes paired $t$ tests.

Tests were also performed on a cohort of WT and $\mathrm{arg}^{-/-}$mice at P21 and 7 weeks of age. Weanling mice were first allowed to habituate to the open field for $20 \mathrm{~m}$ and gently removed while the two identical objects were placed in the field. Weanlings were then immediately replaced and allowed to accumulate $30 \mathrm{~s}$ of total exploration time. Weanlings that did not accumulate $30 \mathrm{~s}$ of oral or nasal exploration within $6 \mathrm{~m}$ were excluded. Forty-eight hours later, mice were again placed in the field with one familiar and one novel object and were removed when $30 \mathrm{~s}$ of exploration had been accumulated. Mice were retested 4 weeks later as described in the initial novel object recognition experiment, but with a new set of objects (black and white disc and folded standard index card). The location of the novel object was again counterbalanced, and exploration was videotaped and scored by a single blinded observer. Exploration time on days 1 and 3 were analyzed by two-factor (genotype vs location or object type) RM-ANOVA followed by a post hoc Student's $t$ test. 
Immunoprecipitations. Hippocampi were dissected in ice-cold PBS and homogenized in lysis buffer (20 mM Tris, pH 7.5, $150 \mathrm{~mm} \mathrm{NaCl}$, 2 mм EDTA, 1\% Triton X-100, and protease and phosphatase inhibitors). The protein concentration of each extract was determined using the BCA detergent-compatible protein assay kit (Pierce). Total protein extract $(0.5-1 \mathrm{mg})$ was precleared with $50 \mu \mathrm{l}$ of protein G Plus/A agarose beads (Calbiochem, San Diego, CA) for 30 $\min$ at $4^{\circ} \mathrm{C}$. Two micrograms of antip190RhoGAP monoclonal antibody (mAb) were incubated with $0.5-1 \mathrm{mg}$ of total extract for $2 \mathrm{~h}$ or overnight at $4^{\circ} \mathrm{C}$ with gentle mixing. Then, $30 \mu \mathrm{l}$ of protein G Plus/A agarose beads (pre-equilibrated) was added, and immune complexes were incubated for $1 \mathrm{~h}$ at $4^{\circ} \mathrm{C}$. Immunoprecipitates were washed three times with $1 \mathrm{ml}$ of lysis buffer, mixed with sample buffer, and separated by SDS-PAGE for immunoblot analysis. Coimmunoprecipitated proteins and loading controls were detected by stripping and reprobing the blot with anti-120 RasGAP $\mathrm{mAb}$ and anti-phosphotyrosine (4G10; Upstate Biotechnology, Charlottesville, VA). Bands were quantified using a densitometer and ImageQuant software.

Rho activity assays. Under heavy sedation with Nembutal, mouse brains were rapidly excised, hippocampi were lysed in buffer, and Rho activity was assayed as described previously (Bradley et al., 2006).

\section{Results}

\section{Hippocampal dendrite arbors are} smaller in arg $^{-/-}$mice

We used biocytin injection followed by camera lucida reconstruction to examine the structure of hippocampal CA1 pyramidal neurons in mice lacking $\mathrm{Abl}$ and/or Arg (Fig. 1A). Both Sholl and morphometric analyses reveal that CA1 pyramidal neurons in 6- to 8 -week-old $\mathrm{arg}^{-1-}$ mice have smaller apical dendrite arbors compared with WT controls (Fig. $1 B, D)$. Quantitation revealed that the total length of apical dendrites is reduced $27 \%$ in $\mathrm{arg}^{-1-}$ neurons compared with WT neurons (Fig. 1D). These smaller apical dendrite arbors have $31 \%$ fewer dendrite branches (Fig. 1 E) and a commensurate decrease in the number of apical dendrite segments compared with WT neurons. Basal dendrite length and branchpoints are more modestly reduced in $\mathrm{arg}^{-/-}$CA1 pyramidal neurons relative to wild type at this stage in development, but these reductions are not statistically significant. After staining of serial P42 hippocampal sections with antiNeuN antibodies to stain neurons, we used unbiased quantitative stereology to estimate CA1 pyramidal neuron density. This analysis revealed that CA1 pyramidal neurons are $29 \%$ more densely packed in the CA1 pyramidal layer of P42 $\mathrm{arg}^{-/-}$mice $\left(3.41 \pm 0.32 \times 10^{5} / \mathrm{mm}^{3}\right)$ than in the WT mice $\left(2.62 \pm 0.14 \times 10^{5} / \mathrm{mm}^{3}\right)(n=12$ sections, 2 mice, for each genotype).

In contrast to the defects observed in $\mathrm{arg}^{-/-}$neurons, $a b l^{-/-}$ CA1 pyramidal neurons are similar in shape, length, and branchpoint number to WT neurons (Fig. $1 B-E$ ). We previously showed
2. Section and stain

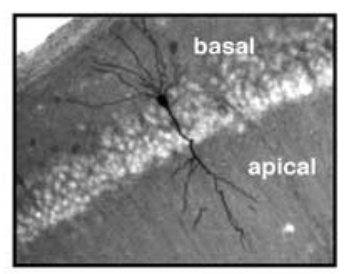

3. Trace and reconstruct

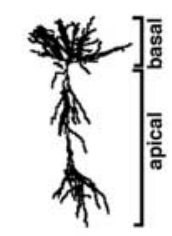

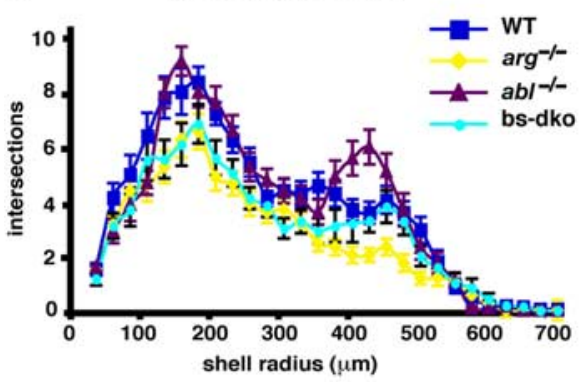

D

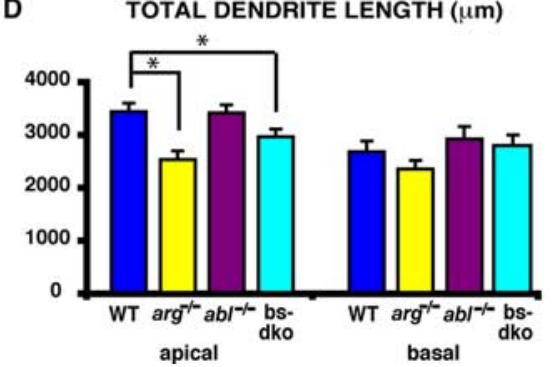

C

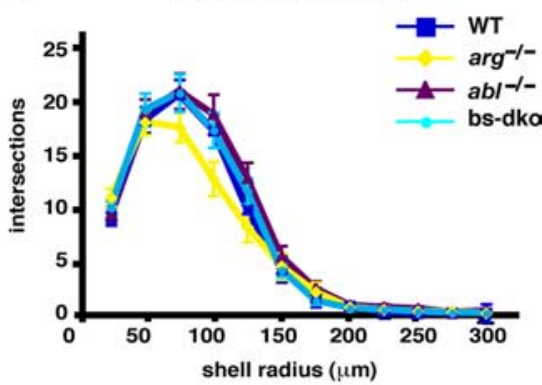

E

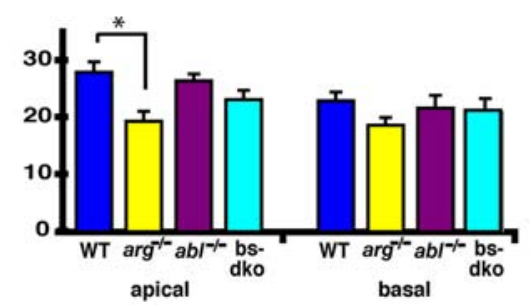

Figure 1. Hippocampal dendrite arbors are reduced in adult $\arg ^{-1-}$ mice. $\boldsymbol{A}$, Labeling and morphometric analysis of hippocampal CA1 pyramidal neurons. Individual live neurons in acute hippocampal slices were injected with biocytin using sharp (1). Hippocampal sections were fixed, sectioned, and stained using streptavidin-HRP-conjugates (2). Individual slices -I- $a b l^{-/-}$, and bs-dko hippocampal CA1 pyramidal neurons. Sholl analysis measures dendrite complexity: concentric

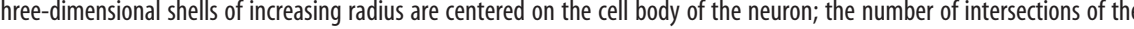
dendrite arbor with a given shell is plotted versus the shell radius. Each point represents mean \pm SE. For all data shown, analysis

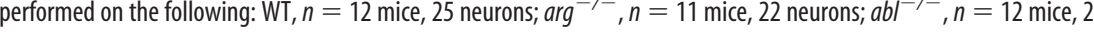
dendrite arbors from WT, $a l^{-/-}, a r g^{-/-}$, and bs-dko hippocampal CA1 pyramidal neurons. Error bars indicate mean + SE. Data for ANOVA between all genotypes are as follows: apical length, $p=0.0034$; basal length, $p=0.3376$; apical branchpoints, $p=$ 0.0128; basal branchpoints, $p=0.3104$; post hoc Student-Newman-Keuls test for each mutant versus wild type, ${ }^{*} p<0.05$.

that brain-specific $a b l-/-\mathrm{arg}^{-/-}$mice (bs-dko mice), which genetically lack Abl and Arg in all brain neurons, exhibit more severe reductions in cortical dendrites than $\mathrm{arg}^{-/-}$mice (Moresco et al., 2005), indicating that $\mathrm{Abl}$ and Arg have overlapping roles in cortical dendrite arbor stabilization. Surprisingly, bs-dko hippocampal CA1 pyramidal neurons exhibit only modest reductions in apical dendrite length and branches, 14 and $17 \%$, respectively, but only the reduction in length is statistically significant (Fig. $1 D, E$ ). Thus, although $\mathrm{Abl}$ is not essential for dendrite arbor appearance, the loss of Abl function can partially suppress the dendrite defects observed in $\mathrm{arg}^{-/-}$hippocampal CA1 pyramidal neurons.

We examined whether differences between Abl and Arg expression levels might explain the differential requirements for $\mathrm{Abl}$ and Arg in hippocampal dendrite development. We used quantitative immunoblotting with purified recombinant $\mathrm{Abl}$ and Arg as standards to measure the Abl and Arg levels in hippocampal extracts (supplemental Fig. 1, available at www.jneurosci.org as supplemental material). Arg is 15 -fold more abundant than 
A

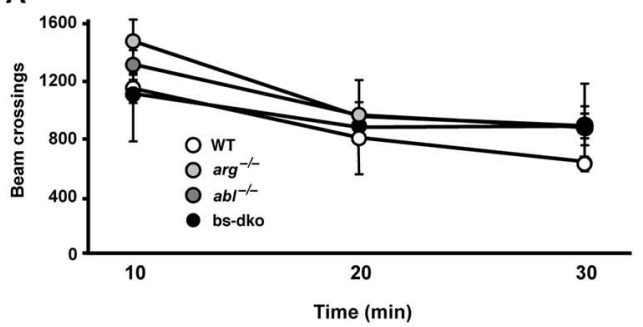

B

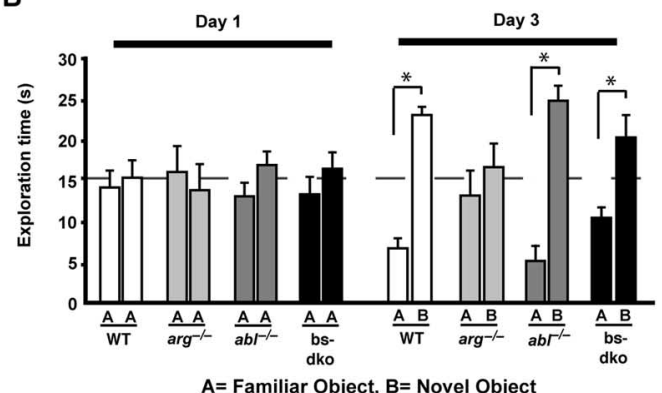

C

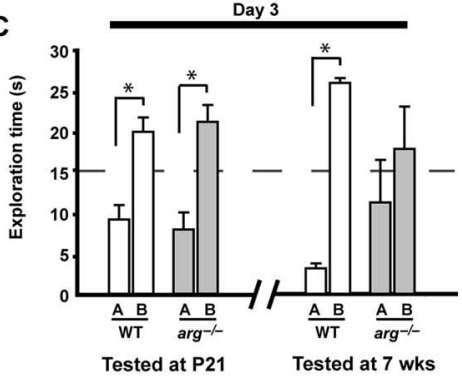

D

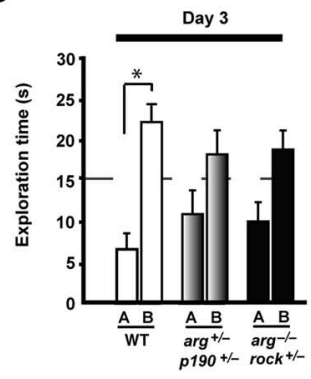

Figure 2. $\mathrm{arg}^{-1-}$ mice exhibit deficits in a hippocampus-dependent novel object recognition task. $\boldsymbol{A}$, Habituation of WT, $\arg ^{-1-}, a b l^{-1-}$, and bs-dko mice to test cage environment. Locomotor activity was measured by the number of photobeams broken in the test cage. Two-factor RM-ANOVA revealed a significant effect of time $(p<0.001)$ but no interaction between genotype and time ( $p=0.6$ ), indicating that all groups habituated to the testing environment equally. For all data shown in $A$ and $\boldsymbol{B}$, analysis was performed on the following:WT, $n=11$ mice; $\mathrm{arg}^{-1-}, n=8$ mice; $\left.a b\right|^{-1-}, n=6$ mice; bs-dko, $n=7$ mice. $B$, Performance of WT, $\mathrm{arg}^{-/-}, a \mathrm{bl}^{-/-}$, and bs-dko mice in an object recognition task. The amount of time exploring each of two identical objects (Familiar, A) is shown on day 1. The amount of time exploring one familiar and one novel object (Novel, B) is shown on day 3. On day 1, exploration time is equally distributed between two identical objects in all genotypes. On day 3, WT, $\mathrm{abl}^{-/-}$, and bs-dko mice display preferred exploration of the novel object, indicated by increased exploration time. $\mathrm{arg}^{-/-}$mice exhibit no preference between familiar and novel objects. Data for two-factor (genotype vs object type) RM-ANOVA are as follows: day 1: location, $p=0.57$; interaction, $p=0.80$; day 3: object type, $p<0.001$; interaction, $p=0.045$; posthoc Student's $t$ test for WT, $a b l^{-1-}$, and bs-dko, ${ }^{*} p<0.05 ;$ arg $^{-1-}, p=0.2$. C, Performance of a cohort of WT and arg $^{-1-}$ at P21 and 7 weeks of age in the object recognition task. Exploration time was equally distributed between two identical objects in both genotypes on day 1 in all tests as in $\boldsymbol{B}$ above (data not shown). At P21, both WT and arg $-1-$ mice show a preference for the novel object (B) during testing on day 3. By 7 weeks, arg $^{-1-}$ mice show no significant preference between familiar (A) and novel (B) objects. $n=9$ WT mice and $7 \mathrm{arg}^{-1-}$ mice. Data for two-factor RM-ANOVA are as follows: day 1: pups, location, $p=0.38$; interaction, $p=0.63$; 7-week-old mice, location, $p=0.95$; interaction $p=0.2$; day 3: object type, $p<0.001$ for P21 mice with no interaction effect ( $p=0.3$ ); interaction effect, $p=0.003$ for 7-week-old mice; post hoc pairwise Student's $t$ test, ${ }^{*} p<0.05 ; 7$-week-old arg $^{-1-}$ mice, $p=0.11$. D, Performance of WT, arg $^{+/-} p 190^{+/-}$, and $\mathrm{arg}^{-/-}$rock $^{+/-}$mice in an object recognition task. On day 1 , exploration time is equally distributed between two identical objects in all genotypes (data not shown). On day 3, WT mice show a preference for the novel object, whereas $\mathrm{arg}^{+/-} \mathrm{p} 190^{+/-}$, and $\mathrm{arg}^{-/-} \mathrm{rock}^{+/-}$mice show no significant preference between familiar (A) and novel (B) objects. $n=7$ WT mice, $7 \mathrm{arg}^{+/-} p 190^{+/-}$mice, and $7 \mathrm{arg}^{+/-} p 190^{+/-}$mice. Data for two-factor (genotype vs object type) RM-ANOVA are as follows: day 1: location, $p=0.09$; interaction, $p=0.68$; day 3 : object type, $p<$ 0.001 ; interaction, $p=0.4$; paired ttests, ${ }^{*} p<0.05 ; \mathrm{arg}^{+/-} p 190^{+/-}, p=0.09 ; \mathrm{arg}^{-1-} \mathrm{rock}^{+/-}, p=0.20$. Error bars indicate mean $\pm S E$.

Abl in hippocampal extracts (supplemental Fig. 1, available at www.jneurosci.org as supplemental material), consistent with its more prominent role in regulating dendritic arbor stability. Interestingly, Abl levels are increased fourfold in $\mathrm{arg}^{-/-}$hippocampus extracts relative to wild type. A similar upregulation of $\mathrm{Abl}$ is not observed in $\mathrm{arg}^{-/-}$cortical extracts (Moresco et al., 2005).

\section{$\mathrm{arg}^{-/-}$mice perform poorly in a hippocampus-dependent} object recognition task

Because $\mathrm{arg}^{-/-}$mice exhibit a selective loss of hippocampal CA1 dendrites, we examined whether hippocampal function was altered in these mice. The object recognition task capitalizes on rodents' innate tendency to explore novel items placed in a familiar environment.

Twelve- to 16-week-old male WT, abl-/-, $\mathrm{arg}^{-/-}$, and bsdko mice were first habituated to the test cages. Mice of all geno- types habituate similarly to the novel environment of the test cage, as demonstrated by a time-dependent reduction in locomotor activity (Fig. 2A). Mice were then allowed to explore two identical objects for a total of $30 \mathrm{~s}$. After $48 \mathrm{~h}$, the mice were placed in the test cage containing one familiar and one novel object. WT, $a b l-/-$, and bs-dko mice exhibit the expected increase in exploration of the novel object, but $\mathrm{arg}^{-1-}$ mice exhibit no preference for the novel object (Fig. 2B). This deficit in hippocampus-dependent behavior in $\mathrm{arg}^{-1-}$ mice mirrors the reductions in hippocampal dendrite arbor complexity.

We then used the novel object recognition task to measure hippocampusdependent behavior in a cohort of WT and $\mathrm{arg}^{-/-}$mice throughout development. Interestingly, at P21, both WT and $\arg ^{-/-}$ mice exhibit the expected increase in exploration of the novel object. However, by 7 weeks of age, $\mathrm{arg}^{-1-}$ mice exhibit no clear preference for the novel object, whereas the WT mice maintain the normal increased exploration of the novel object (Fig. 2C).

\section{Apical dendrite arbors develop normally in $\mathrm{arg}^{-/-}$mice but later regress}

Behavioral testing indicated that hippocampal function is normal in P21 $\mathrm{arg}^{-1-}$ mice but that it becomes reduced as $\mathrm{arg}^{-/-}$mice age to adulthood. We examined whether structural alterations of hippocampal CA1 pyramidal neurons might mirror this age-dependent loss of hippocampal function. We focused on the apical arbors because these were most affected in $\mathrm{arg}^{-/-}$mice (Fig. 1D,E).

In WT mice, apical arbors had essentially reached their fully mature size by $\mathrm{P} 18-\mathrm{P} 21$, as reported previously (Burt, 1980), and exhibited a modest expansion as the mice aged up to 3.5-4 months of age. Of special interest, the apical arbors of P18-P21 $\mathrm{arg}^{-/-}$neurons are similar in size and branchpoint number to WT neurons at P18-P21 (Fig. $3 A, B$ ). However, the apical arbors of the CA1 pyramidal neurons in the $\mathrm{arg}^{-/-}$mice are reduced in length and branches by $\mathrm{P} 30-\mathrm{P} 31$. Further apical arbor shrinkage was observed in $\mathrm{arg}^{-/-}$neurons 6-8 weeks of age, but arbors did not shrink further between this age and 3.5-4 months of age (Fig. $3 A, B$ ). These findings indicate that apical dendrite arbors of hippocampal CA1 pyramidal neurons initially develop normally in $\mathrm{arg}^{-/-}$mice but lose branches and length as the mice mature to adulthood.

\section{Shaffer collateral-CA1 synapse loss precedes the reduction in $\mathrm{arg}^{-/-}$apical dendrite arbors}

Arg localizes to excitatory synapses made between Schaffer collateral axons and the apical dendrites of hippocampal CA1 synapses (SC-CA1 synapses) (Koleske et al., 1998), suggesting that 
Arg might regulate dendrite stability by controlling synaptic structure or function.

To test the possibility that Arg may influence SC-CA1 synapses, we determined whether the number or morphology of SC-CA1 synapses is altered in $\mathrm{arg}^{-/-}$ mice. SC-CA1 synapses were identified by the presence of a dendritic spine containing a PSD apposed to a presynaptic compartment containing at least three synaptic vesicles (Fig. $3 C, D$ ). In the WT mice, the synapse density (number of synapses per unit area) does not change significantly from P21 to P42 (Fig. 3E). However, although SC-CA1 synapse density is similar in WT and $\mathrm{arg}^{-/-}$mice at P21, it is reduced by $43 \%$ in $\mathrm{arg}^{-1-}$ mice at P31 and by $30 \%$ at $\mathrm{P} 42$ (Fig. $3 E$ ). The $43 \%$ reduction in synapses at P31 is greater than the reduction in dendrite arbors (13\%) observed in $\mathrm{arg}^{-/-}$neurons (Fig. $3 A, B$ ), and no reduction in branchpoints was observed at this time point, suggesting that synapse loss precedes dendrite arbor shrinkage. The observed reduction in synapses at P42 (30\%) is strikingly similar to the reductions in apical dendrite arbor (27\%) observed in $\mathrm{arg}^{-1-}$ neurons over the same developmental period. Together, these findings strongly suggest that the reduction in dendritic arbors in $\mathrm{arg}^{-/-}$mice results from a defect in synapse maintenance between P21 and P42.

\section{Dendritic spine morphogenesis is abnormal in $\mathrm{arg}^{-/-}$mice}

The localization of Arg to dendritic spines (Moresco et al., 2003) suggests it might mediate morphological changes during spine maturation. We closely monitored spine morphology in WT and $\mathrm{arg}^{-/-}$mice during development to examine a possible role for Arg in spine morphogenesis.

We measured dendritic spine area for multiple SC-CA1 synapses as a characteristic of spine head morphology. A plot of spine head areas in WT mice at P21 reveals a broad distribution, which reflects overall heterogeneity of spine head size at this point in development. Between P21 and P42, spines undergo a morphological transition in which there is a $30 \%$ reduction in mean area (Fig. $4 A$ ) in WT animals. In addition to an overall reduction in size, the variance in spine areas in WT animals was reduced by $71 \%$ between these time points $(p<0.0001$, two-tailed $F$ test for variance).

Like WT mice, dendrite spines are heterogeneous in size in $\mathrm{arg}^{-1-}$ mice at P21. However, spine areas do not transition into a more homogenous size between P21 and P42 in $\mathrm{arg}^{-/-}$mice. The means and variances of spine area become slightly reduced between P21 and P42, but neither change is statistically significant ( $p=0.44$ and $p=0.39$, respectively). Importantly, we included only PSDcontaining spines that are apposed to vesicle-filled presynaptic termini for these measurements. Thus, the data for $\mathrm{P} 42 \mathrm{arg}^{-/-}$mice do not account for spines that may have already deteriorated.
We also measured dendritic spine head width ( $\mathrm{dh}$ ) and neck width $(\mathrm{dn})$ for multiple SC-CA1 synapses and examined the ratio of these measurements $(\mathrm{dh} / \mathrm{dn})$ as an overall measure of spine shape. As in spine head areas, a plot of $\mathrm{dh} / \mathrm{dn}$ ratios in WT mice at P21 reveals a broad distribution, which reflects the significant spine shape heterogeneity at this point in development. Spines undergo a morphological transition in WT mice between P21 and P42 in which they assume a narrower overall distribution of shapes, leading to a reduction in $\mathrm{dh} / \mathrm{dn}$ variance from $\mathrm{P} 21$ to $\mathrm{P} 42$. Although we observe significant heterogeneity in spine shape by this $\mathrm{dh} / \mathrm{dn}$ measurement in $\arg ^{-1-}$ at P21, we do not observe the morphological transition to a more homogeneous shape distribution in these mice (data not shown).

Previous reports suggest that the length of the PSD is a valid measurement of synaptic strength (Schikorski and Stevens, 1997). Therefore, we also analyzed the length of the PSD in WT and $\mathrm{arg}^{-1-}$ mice to identify other possible discrepancies. In WT 
A

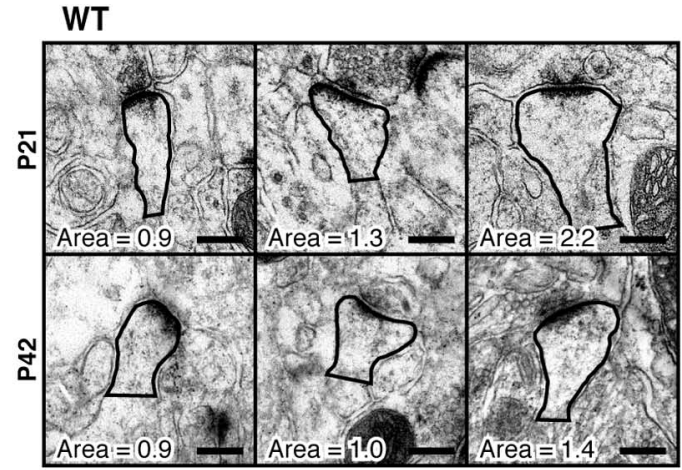

B
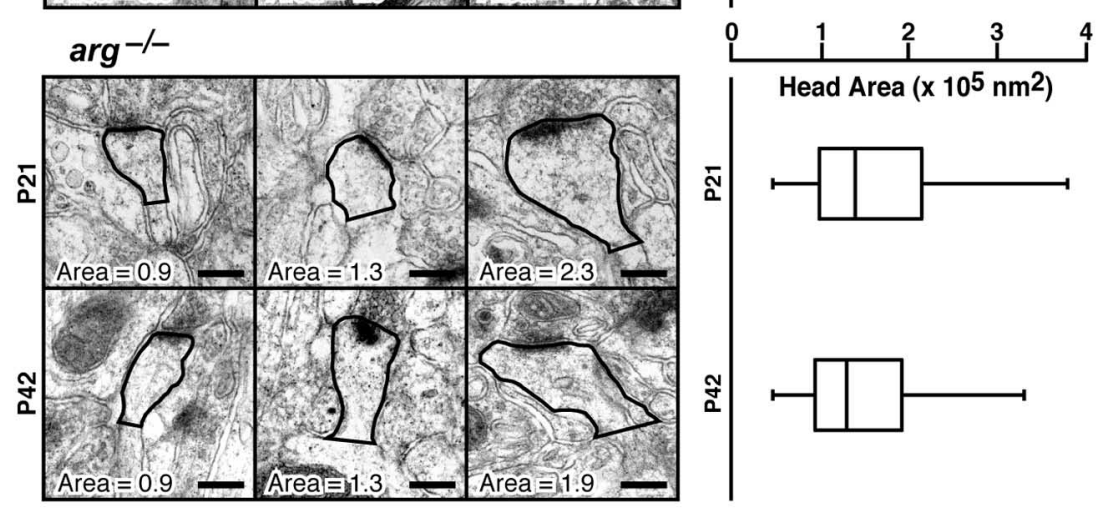

C

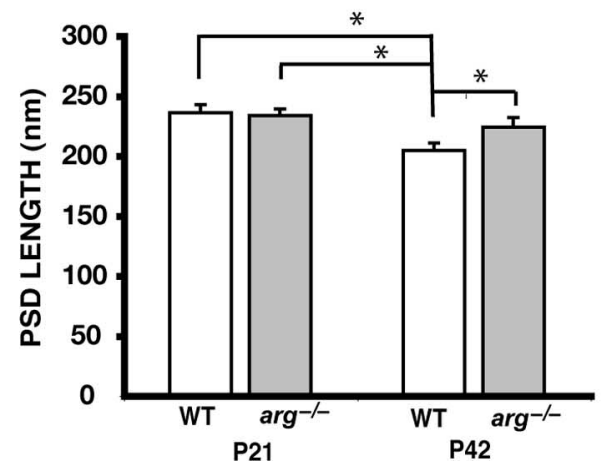

Figure 4. The morphological maturation of spines is altered in $\arg ^{-/-}$mice. $A, B$, Hippocampal dendritic spine cross-sectional areas in WT $(\boldsymbol{A})$ and $\arg ^{-1-}(\boldsymbol{B})$ mice at P21 and P42. Representative spines and areas are shown on the left. Plots of spine areas are shown on the right. WT spines exhibit a $30 \%$ reduction in the mean area between $\mathrm{P} 21$ and $\mathrm{P} 42$. In addition, a two-sample $F$ test shows a statistically significant $(71 \%)$ decrease in variance in WT spines from P21 to P42 ( $p<0.0001$, two-tailed $F$ test for variance). arg $^{-/-}$spines do not exhibit a significant reduction in mean area from P21 to P42, and their variances are statistically equivalent. Quantitation was performed on the following mice: P21 WT, $n=68$ synapses, 3 mice; P21 $\mathrm{arg}^{-1-}, n=65$ synapses, 3 mice; P42 WT, $n=60$ synapses, 3 mice; adult arg $^{-/-}, n=61$ synapses, 3 mice. ANOVA between all genotypes and time points, $p<0.0001$; post hoc Student-Newman-Keuls test for significance, ${ }^{*} p<0.05$. Scale bars, $200 \mathrm{~nm}$. C, Average PSD length (nanometer) in WT and $\mathrm{arg}^{-/-}$mice at P21 and P42. Quantitation was performed on the same dataset used to quantitate synapse density in Figure $3 E$. One hundred fifteen PSD measurements were made for each of the four age/genotype combinations. ANOVA between all genotypes and time points, $p=0.004$; post hoc Student-Newman-Keuls test for significance, ${ }^{*} p<0.05$.

animals, mean PSD length is reduced by a statistically significant $13 \%$ from P21 to P42 (Fig. 4C). This reduction in PSD length may relate to the reduction in spine area observed in WT mice over this same period (Fig. 4A). Interestingly, this change is not observed in $\mathrm{arg}^{-1-}$ mice in which the mean PSD length is reduced only slightly from P21 to P42.

Finally, to examine whether defects in spine morphogenesis resulted from alterations in dendritic spine formation in $\mathrm{arg}^{-1-}$ mice, we also examined spine density on apical dendrites of WT and $\mathrm{arg}^{-1-}$ neurons by imaging CA1 pyramidal neurons labeled with a green fluorescent protein (GFP) transgene [line M1 (Feng et al., 2000)]. Spine-like protrusions are present at similar densi- ties in WT and $\mathrm{arg}^{-/-}$mice at P21 (supplemental Fig. $2 C$, available at www.jneurosci.org as supplemental material), but spine density along dendritic segments becomes reduced by $21 \%$ in the $\mathrm{arg}^{-1-}$ mice by P42 (supplemental Fig. 2D, available at www.jneurosci.org as supplemental material). Importantly, analysis of GFP-labeled neurons confirmed the finding (Fig. $4 A, B)$ that dendritic spines are larger and more heterogeneous in $\mathrm{arg}^{-/-}$neurons than in WT neurons at P42 (supplemental Fig. 2E, available at www.jneurosci.org as supplemental material). These findings indicate that $\mathrm{Arg}$ is not required for spine formation but is required for spine maintenance.

\section{p190RhoGAP phosphorylation and binding to p120RasGAP are reduced in $\mathrm{arg}^{-/-}$hippocampus}

After integrin-mediated fibroblast adhesion to fibronectin, Arg acts via its substrate p190RhoGAP (p190) to inhibit Rho and attenuate actomyosin contractility (Hernandez et al., 2004; Bradley et al., 2006; Peacock et al., 2007). As a first step toward understanding whether p190 mediates the effects of Arg on hippocampal synapse morphology and dendrite stability, we examined p190 localization and activity.

Arg is enriched in synaptic fractions (synaptoneurosomes) relative to crude homogenate (Koleske et al., 1998). Similarly, p190 is enriched at least fivefold in purified hippocampal synaptoneurosomes relative to crude hippocampal homogenate (Fig. $5 A)$. Enrichment of p190 in synaptoneurosomes suggests a possible role in mediating the activity of Arg on spine morphology and dendrite stability. Consistent with this, immunoelectron microscopy reveals significant p190 localization in dendritic spines at SC-CA1 synapses (Fig. 5B).

Phosphorylation of p190 on tyrosine 1105 by Arg promotes its binding to p120RasGAP, resulting in p190 recruitment to the membrane where it inhibits Rho (Bradley et al., 2006). As indicators for p190RhoGAP activity, we monitored p190 phosphorylation status and binding to p120RasGAP in WT and $\mathrm{arg}^{-/-}$hippocampal extracts at different stages in development. Immunoprecipitation of p190 from hippocampal extracts followed by immunoblotting with antiphosphotyrosine antibodies revealed that p190 phosphorylation is reduced 43 and 30\% in hippocampal extracts made from $\mathrm{arg}^{-1-}$ mice at P21 and P42, respectively, relative to control hippocampal extracts from WT mice (Fig. 5C,D). Levels of p120RasGAP that coimmunoprecipitate with p190 are also reduced by 36 and $35 \%$ at P21 and $\mathrm{P} 42$, respectively, in $\mathrm{arg}^{-1-}$ mice hippocampal extracts relative to WT extracts (Fig $5 C, E$ ).

These observations strongly suggested that p190RhoGAP activity is reduced in $\mathrm{arg}^{-1-}$ hippocampus and led us to test 
whether Rho activity is increased in these mice. Indeed, Rho activity is increased 35 and $21 \%$ in P21 and P42 hippocampal extracts, respectively, relative to age-matched WT hippocampal extracts (Fig. 5F). Together, these data indicate that p190RhoGAP activity is reduced in the $\mathrm{arg}^{-/-}$hippocampus, and this is accompanied by an increase in Rho activity.

\section{Arg and p190RhoGAP interact} functionally to regulate hippocampal synapse and dendrite morphogenesis Our findings that p190RhoGAP localizes to dendritic spines and that its activity is reduced in $\mathrm{arg}^{-/-}$mice suggests that Arg acts via p190RhoGAP to regulate dendrite stability. We used genetics to examine a possible functional interaction between Arg and p190RhoGAP during dendrite arbor formation/stabilization. Six- to eightweek-old $\mathrm{arg}^{+/-}$or p190rhogap ${ }^{+/-}$single heterozygotes have hippocampal apical dendritic arbors that are similar in length (Fig. $6 A$ ) and branchpoints (Fig. 6B) to WT mice. In contrast, apical dendrite arbors in $\mathrm{arg}^{+/}$ - p190rhogap ${ }^{+/-}$double heterozygotes are $19 \%$ shorter and have 23\% fewer branches than control WT animals (Fig. 6A, B). SCCA1 synapse density is reduced by $28 \%$ in P42 arg $^{+/-}$p190rhogap ${ }^{+/-}$mice relative to wild type, a reduction similar to the $30 \%$ reduction observed in $\mathrm{arg}^{-1-}$ animals (Fig. 6E). Like $\mathrm{arg}^{-1-}$ mice, spine head sizes are larger and more heterogeneous in $\mathrm{arg}^{+/}$ - p190rhogap ${ }^{+/-}$mice than in WT animals (Fig. 6 F). Rho activity is also increased by $37 \%$ in P42 $\mathrm{arg}^{+/-}$p190rhogap ${ }^{+/-}$hippocampi relative to WT control hippocampi (Fig. 5G). Together, these findings suggest that reduced Arg: p190RhoGAP-dependent Rho inhibition contributes to the synaptic and dendritic defects observed in arg $^{+/-}$p190rhogap ${ }^{+/-}$brains.

We also examined the consequences of the reduced synapse density and dendrite size on the behavior of $\mathrm{arg}^{+/-}$ p190rhogap $^{+/-}$mice using the novel object recognition task. Seven-week-old arg $^{+/-}$p190rhogap ${ }^{+/-}$mice showed little preference for the novel object in this test, whereas WT control animals showed a marked preference for the novel object (Fig. 2D).

\section{Reducing gene dosage of the Rho} effector ROCKII suppresses dendritic regression in $\mathrm{arg}^{-/-}$ mice but enhances synapse loss

The brain-specific p160 isoform of Rho kinase (ROCKII) is a major effector of Rho signaling in the brain (Hirose et al., 1998; Mueller et al., 2005). Under normal conditions, Arg acts via p190RhoGAP to inhibit Rho activity. These data suggest that hyperactive Rho signaling through ROCKII may contribute to
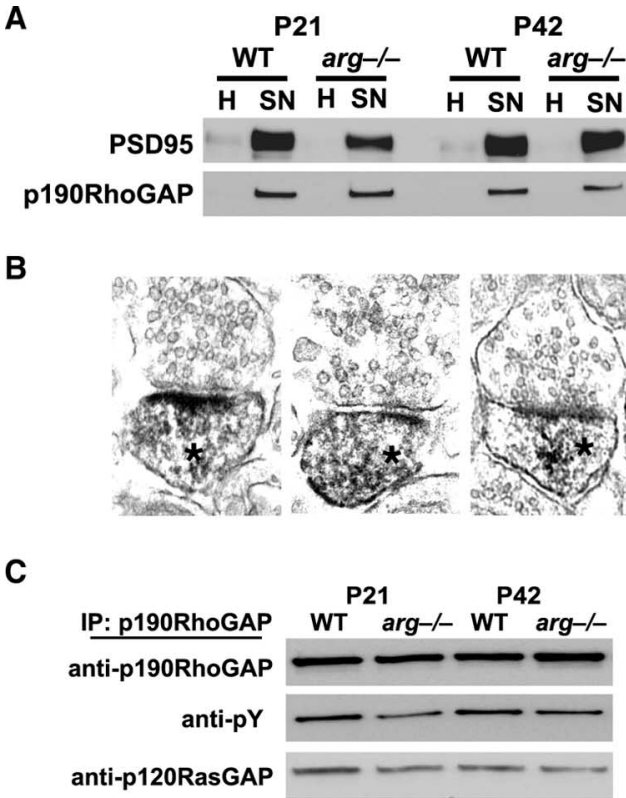

$\mathbf{F}$

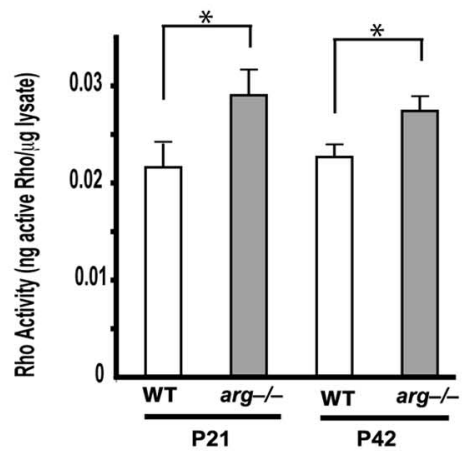

Figure 5. p190RhoGAP phosphorylation and binding to p120RasGAP and Rho activity are disrupted in $\arg ^{-/-}$mice. $\boldsymbol{A}$, Immunoblotting analysis of p190RhoGAP from WT and arg $^{-/-}$hippocampus at P21 and P42. Fifteen micrograms of total protein from crude homogenate $(\mathrm{H})$ or synaptoneurosome $(\mathrm{SN})$ preparations were loaded onto an SDS-PAGE gel and immunoblotted with antibodies to PSD protein 95 (PSD95) or p190RhoGAP. B, Immunoelectron microscopic localization of p190RhoGAP in SC-CA1 synapses. Synapses are oriented with presynaptic compartment at the top and dendritic spine at the bottom. Darkimmunopositive staining for p190RhoGAP appears in the dendritic spine and is indicated by asterisks. C, Representative example of p190RhoGAP immunoprecipitation (IP) analysis. p190RhoGAP was immunoprecipitated from hippocampal homogenates made from WT or arg $^{-1-}$ mice at P21 or P42. The blots were probed with anti-p190RhoGAP and anti-p120RasGAP. Blots were also probed with anti-phosphotyrosine (anti-PY), and the signal corresponding to p190RhoGAP is shown. D, Quantitation of p190RhoGAP phophorylation. Bands from immunoprecipitation experiments were quantified by densitometry. The values are the ratios of intensity of the pY band to p190RhoGAP and normalized to WT controls. $n=4$ sets of mice. Student's $t$ test for significance, ${ }^{*} p<0.05$. E, Quantitation of p190RhoGAP-associated p120RasGAP. Bands from immunoprecipitation experiments were quantified by densitometry. The values are the ratios of intensity of p120RasGAP band to p190RhoGAP and normalized to WT controls. $n=3$ sets of mice. Student's $t$ test for significance, ${ }^{*} p<0.05$. F, Quantitation of Rho activity. Rho activity measured in hippocampal lysates made from WT or $\mathrm{arg}^{-/-}$mice at P21 or P42 is shown. Values are expressed as the amount of active Rho per microgram of lysate protein. $n=7$ pairs of mice for each time point. Student's $t$ test for significance, ${ }^{*} p<0.05$. G, Quantitation of Rho activity. Rho activity measured in hippocampal lysates made from WT, $\arg ^{+/-}$p190rhogap $^{+/-}\left(\arg ^{+/-} \mathrm{pl}^{190^{+/-}}\right)$, or $\arg ^{-/-}$rockll $^{+/-}\left(\right.$arg $^{-/-}$rock $\left.^{+/-}\right)$P42 mice is shown. WT data are the same as in $\boldsymbol{F} . n=4$ pairs of mice for $\arg ^{+/-} p 190^{+/-}$ and $\arg ^{-/-}$rock $^{+/-}$mice. Student's $t$ test for significance, ${ }^{*} p<0.05$. Error bars indicate mean \pm SE.

the dendritic regression observed in $\mathrm{arg}^{-/-}$mice. We hypothesized that reducing ROCKII levels in the brain might suppress the hippocampal dendritic regression observed in $\mathrm{arg}^{-/-}$mice. In contrast to $\mathrm{arg}^{-/-}$mice, which exhibit significant reduction of apical dendrite length and branchpoints at 6-8-weeks of age, $\mathrm{arg}^{-1-}$ mice that are also heterozygous for a rockII mutation

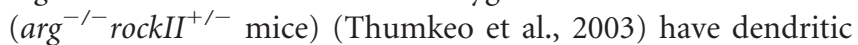


A APICAL DENDRITE LENGTH $(\mu \mathrm{m})$ B APICAL BRANCHPOINTS

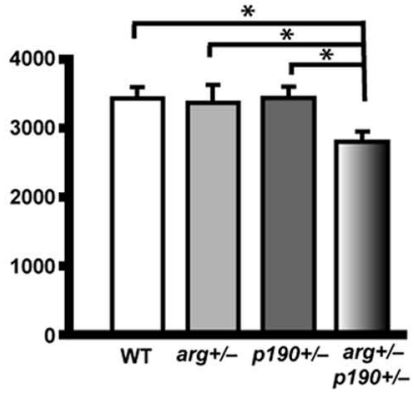

C

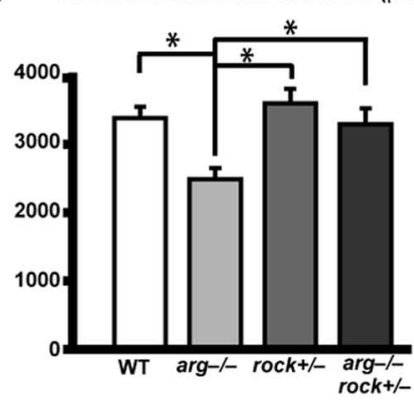

E

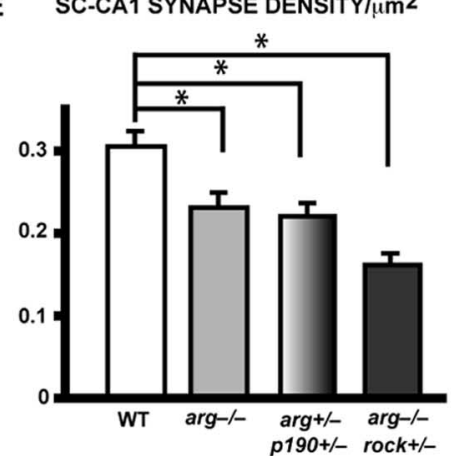

D

APICAL BRANCHPOINTS

F SPINE HEAD AREA $\left(\mu \mathrm{m}^{2}\right)$
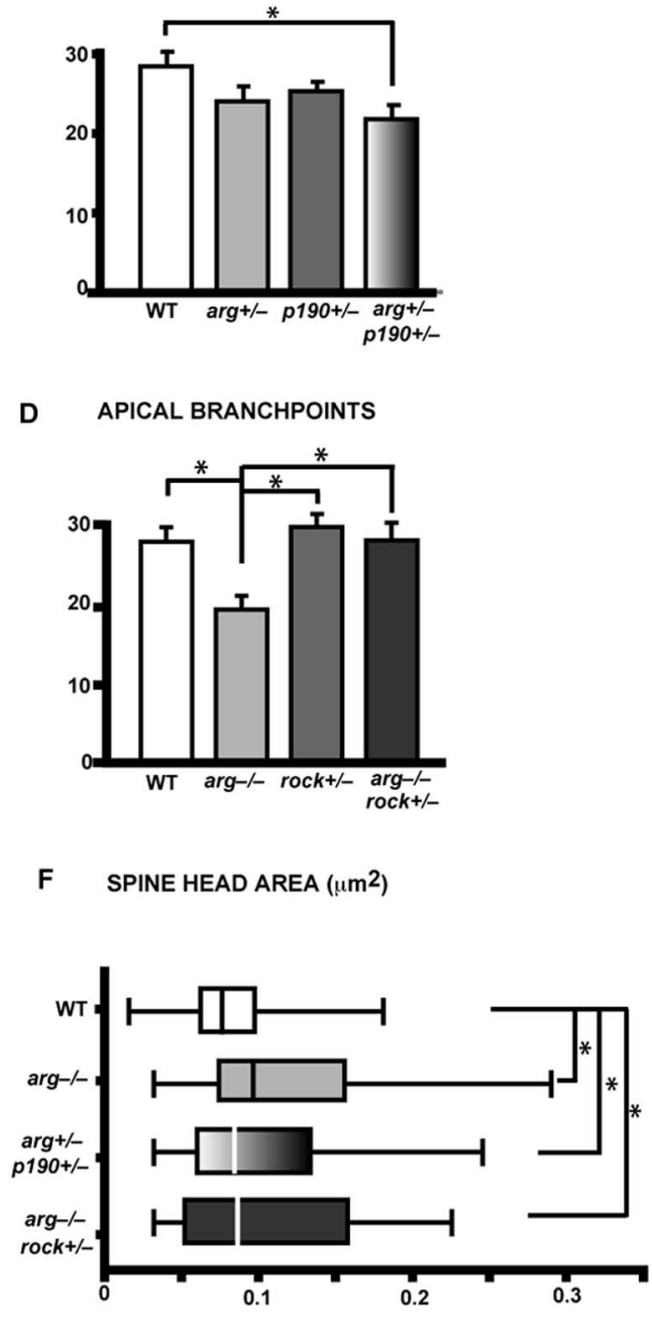

Figure 6. Genetic analysis of arg, p190rhogap, and rockll in synapse and dendrite arbor development. $\boldsymbol{A}, \boldsymbol{B}$, Mean total length (A) and branchpoint number $(\boldsymbol{B})$ of apical dendrite arbors from WT, $\arg ^{+/-}$, p190rhogap ${ }^{+/-}\left(\mathrm{p}^{190^{+/-}}\right)$, and $\mathrm{arg}^{+/-}$p190rhogap ${ }^{+/-}\left(\mathrm{arg}^{+/-} \mathrm{p}_{190^{+/-}}\right)$mice at $6-8$ weeks of age. Analysis was performed on the following: WT, $n=12$ mice, 25 neurons; arg $^{+/-}, n=10$ mice, 22 neurons; $p 190^{+/-}, n=11$ mice, 23 neurons; arg $^{+/-} p 190^{+/-}, n=10$ mice, 24 neurons. Data for ANOVA between all genotypes are as follows: length, $p=0.012$; branchpoints, $p=0.036$; post hoc StudentNewman-Keuls test for significance, ${ }^{*} p<0.05$. C, $\boldsymbol{D}$, Mean total length $(\boldsymbol{C})$ and branchpoint number $(\boldsymbol{D})$ of apical dendrite arbors from WT, $\mathrm{arg}^{-1-}$, $\mathrm{rockll}^{+/-}\left(\mathrm{rock}^{+/-}\right)$, and $\mathrm{arg}^{-1-} \mathrm{rockll}^{+/-}\left(\mathrm{arg}^{-/-} \mathrm{rock}^{+/-}\right)$mice at 6-8 weeks of age. Analysis was performed on the following: WT, $n=12$ mice, 25 neurons; arg $^{-1-}, n=11$ mice, 22 neurons; rockll ${ }^{+/-}, n=4$ mice, 16 neurons; $\arg ^{-/-}$rockll $^{+/-}, n=5$ mice, 11 neurons. Data for ANOVA between all genotypes are as follows: length, $p<0.00001$; branchpoints, $p=0.0004$; post hoc Student-Newman-Keuls test for significance, ${ }^{*} p<0.05$. E, SC-CA1 synapse density of WT, $\mathrm{arg}^{-1-}, \mathrm{arg}^{+/-} \mathrm{p190}^{+/-}$, and $\mathrm{arg}^{-1-} \mathrm{rock}^{+/-}$mice at P42. Like $\mathrm{arg}^{-1-}$ mice, SC-CA1 synapse density is reduced in $\arg ^{+/-} \mathrm{p}_{190^{+/-}}$mice relative to WT mice. Unexpectedly, SC-CA1 synapse density is also reduced in $\mathrm{arg}^{-/-}$rock $^{+/-}$mice. Quantitation was performed on the following mice: WT, $n=19$ sections, 2 mice; $\arg ^{-/-}, n=17$ sections, 2 mice; $\mathrm{arg}^{+/-} p 190^{+/-}, n=30$ sections, 2 mice; arg $^{-1-}$ rock $^{+/-}, n=25$ sections, 2 mice. ANOVA between all genotypes, $p<$ 0.0001; post hoc pairwise Student-Newman-Keuls test for significance, ${ }^{*} p<0.05$. $F$, Dendritic spine head area in WT, arg $^{-1-}$, $\mathrm{arg}^{+/-} \mathrm{p}^{190^{+/-}}$, and $\mathrm{arg}^{-/-} \mathrm{rock}^{+/-}$mice at P42. Spine head area was determined as in Figure 4. Quantitation was performed on the following mice: WT, $n=60$ spines, 2 mice; $\arg ^{-/-}, n=61$ spines, 2 mice; $\arg ^{+/-}$p190 $^{+/-}, n=113$ spines, 2 mice; $\arg ^{-/-}$rock $^{+/-}, n=50$ spines, 2 mice. ANOVA between all genotypes, $p=0.001$; post hoc pairwise Student-Newman-Keuls test for significance, ${ }^{*} p<0.05$. Error bars indicate mean \pm SE.

arbors that are similar in length (Fig. 6C) and branchpoint number (Fig. 6D) to WT mice. Control rockII ${ }^{+/-}$mice also have normal apical dendritic arbors. These observations suggest that increased signaling by the Rho effector ROCKII is required for the dendritic regression observed in $\mathrm{arg}^{-1-}$ mice.

We also examined whether reduced ROCKII dosage could suppress the reduced SC-CA1 synapse density and altered dendritic spine morphology in $\mathrm{arg}^{-/-}$mice. Unexpectedly, $\mathrm{arg}^{-/}$ rockII ${ }^{+/-}$mice exhibit a $47 \%$ reduction in SC-CA1 synapse density (Fig. 6E). Like $\mathrm{arg}^{-/-}$mice, hippocampal dendritic spines are large and heterogeneous in $\arg ^{-/-}$rockII $^{+/-}$mice. Thus, although dendrite arbors are larger in $\mathrm{arg}^{-/}$ -rockII ${ }^{+/-}$mice than in $\mathrm{arg}^{-/-}$mice, reduced ROCKII dosage does not suppress Arg-dependent phenotypes at the synaptic level. Consistent with the observed reduction in synapse density, $\mathrm{arg}^{-/-}$rockII ${ }^{+/-}$ mice performed poorly in the novel object recognition task (Fig. 2D). Rho activity was increased in $\mathrm{P} 42 \mathrm{arg}^{-/-}$rockII $^{+/-}$hippocampi by $14 \%$ relative to $\mathrm{P} 42 \mathrm{WT}$ controls (Fig. 5G). These observations also affirm a causative link between increased Rho signaling, defects in synapse structure and stability, and poor performance in the object recognition task.

\section{Discussion}

Rho has a well established role in regulating dendrite arbor formation, but its roles in shaping the maturation and stability of synapses and dendrites are unclear. We report that an Arg- and p190RhoGAPdependent Rho inhibitory pathway acts after dendrite arbor and synapse formation to regulate dendritic spine maturation and synapse and dendritic stability. Disruption of this pathway leads to an increase in Rho activity, which impairs normal dendritic spine morphogenesis, leading to gradual loss of synapses and dendrites and deficits in hippocampaldependent behavior. Our results demonstrate that Rho activity must be actively suppressed during late developmental periods to ensure proper maturation of dendritic spines and maintenance of synapses and dendritic arbors.

Abl and Arg have non-overlapping roles in hippocampal dendrite maintenance The loss of Arg function leads to dendrite regression in cortical layer 5 pyramidal neurons, whereas loss of both Abl and Arg leads to more severe cortical dendritic regression during maturation (Moresco et al., 2005). These data suggest that $\mathrm{Abl}$ and Arg play overlapping roles in the maintenance of cortical dendrite arbors.

We report here the unexpected finding that loss of Abl function can partially suppress the hippocampal dendrite regression observed in $\mathrm{arg}^{-/-}$mice. This genetic analysis indicates that $\mathrm{Abl}$ performs a function that is required for the development of a phenotype in $\mathrm{arg}^{-/-}$mice and points to different functions for 
these kinases in hippocampal dendrites. arg $^{-/-}$fibroblasts, which lack Arg/p190RhoGAP-dependent inhibition of Rho, are hypercontractile and have more prominent adhesions and stress fibers than WT cells (Peacock et al., 2007). Abl mediates signaling from integrin receptors (Lewis et al., 1996). We speculate that the loss of Abl function may reduce adhesion, which would preclude the formation of exaggerated contractile structures in $\mathrm{abl}^{-/-} \mathrm{arg}^{-/-}$ neurons.

Previous findings that $\mathrm{Abl}$ promotes neurite branching and elongation in cultured cortical neurons (Zukerberg et al., 2000; Woodring et al., 2002) and dendrite elaboration in cultured hippocampal neurons (Jones et al., 2004) suggested that Abl might promote dendrite development in vivo. Our genetic studies clearly demonstrate that $\mathrm{Abl}$ is not required for hippocampal dendrite arbor formation in vivo.

\section{Arg acts postsynaptically to promote spine maturation and synapse and dendrite stability}

Harris et al. (1992) have shown that spines are heterogeneous in shape in P15 rats, having thin, mushroom, or stubby shapes in nearly equal proportion. By P70, nearly two-thirds of the spines have the thin morphology (Harris et al., 1992). These observations suggest that spines undergo a transition in shape between the late postnatal period and adulthood. We observed a similar transition to more uniform spine shape with a smaller spine area in WT mice as they age between P21 and P42. As reported previously in rats, we also observe a modest shrinkage of the PSD in mouse hippocampal spines during this period (Harris et al., 1992). Neither of these developmental changes is observed in $\mathrm{arg}^{-1-}$ mice. The failure of $\mathrm{arg}^{-/-}$mice to exhibit a decrease in the length of the PSD in CA1 pyramidal neurons is most likely a further reflection of the postsynaptic site of action. Together, these observations suggest that Arg signaling through p190RhoGAP regulates a morphological transformation of spines between late postnatal periods and adulthood.

Interestingly, $\mathrm{Abl}$ and Arg have also been localized to the neuromuscular junction, where their activity is required for clustering of the acetycholine receptor. These observations raise the possibility that $\mathrm{Abl}$ family kinases might also organize receptor clustering in the postsynaptic compartment in other synapses (Finn et al., 2003).

\section{Dysregulation of Rho leads to spine/synapse degeneration}

Our results indicate that hyperactive Rho signaling underlies the defects in spine maturation and dendritic maintenance in Argdeficient mice. Reductions in synapse number and reduced spine density have similarly been observed in mice lacking p120 Catenin, a cadherin-associated protein that inhibits Rho activity (Elia et al., 2006). However, a recent study suggests that glutamatergic transmission can inactivate Rho in cultured neurons, and this correlates with dendritic spine collapse (Schubert et al., 2006). Together, these data indicate that Rho levels must be carefully balanced to achieve proper spine morphogenesis and maintenance.

Dendritic spine and dendritic arbor abnormalities are found in the brains of individuals with mental retardation (Kaufmann and Moser, 2000), autism (Zoghbi, 2003), schizophrenia (Glantz and Lewis, 2000; Broadbelt et al., 2002), and Alzheimer's disease (Anderton et al., 1998). Identification of the genes responsible for various mental retardation cases has affirmed that dysregulation of Rho family GTPases leads to these development defects (Ramakers, 2000). We highlight here a central role for Arg- and p190RhoGAP-mediated inhibition of Rho in spine morphogen- esis and dendrite maintenance. Importantly, synapse and dendrite loss in mice lacking proper Arg/p190RhoGAP signaling correlates temporally with behavioral deficits in a hippocampusdependent task. These findings raise the possibility that dysfunctional signaling by Arg and p190RhoGAP may contribute to one or more of these neurological disorders.

Synapse loss precedes dendritic regression in $\mathrm{arg}^{-/-}$mice, suggesting that synapse loss leads to dendritic regression in these mice. Heterozygosity for rockII suppresses the dendritic regression observed in $\mathrm{arg}^{-/-}$mice, although it does not suppress the defects in spine morphogenesis or synapse loss in these mice, suggesting that ROCKII activity may be critical for dendritic regression that occurs as a consequence of synapse loss. Importantly, the poor performance of $\mathrm{arg}^{-/}$rock $^{+/-}$mice in the object recognition task argues strongly that the observed behavioral deficits result primarily from reduced synaptic connectivity.

\section{Do Arg and p190RhoGAP mediate signaling from integrin receptors at the synapse?}

Arg and p190RhoGAP mediate the integrin-dependent inhibition of Rho activity in fibroblasts during adhesion to fibronectin (Hernandez et al., 2004; Bradley et al., 2006). Several integrin receptor subunits $(\alpha 3, \alpha 5, \alpha 8, \alpha \mathrm{v}, \beta 1, \beta 3, \beta 5)$ localize to synapses (Einheber et al., 1996; Nishimura et al., 1998; Rodriguez et al., 2000; Chavis and Westbrook, 2001). Genetic ablation or peptide/antibody inhibition reveals that integrins have diverse roles in synapse development (Chavis and Westbrook, 2001; Huang et al., 2006; Shi and Ethell, 2006), synaptic transmission (Kramar et al., 2003; Lin et al., 2003; Bernard-Trifilo et al., 2005; Chan et al., 2006; Huang et al., 2006), synaptic plasticity (Chan et al., 2003, 2006; Huang et al., 2006), and synapse and dendrite stability (Nikonenko et al., 2003; Marrs et al., 2006).

Inhibitor studies in cultured neurons suggest that Arg relays signals from integrins containing $\beta 1$ or $\beta 3$ subunits (Moresco et al., 2005). The results presented here raise the intriguing possibility that Arg and p190RhoGAP mediate signaling from synaptic integrin receptors to modulate spine shape and synapse and dendrite stability. In support of this hypothesis, antibody inhibition of integrin $\beta 1$ function leads to synapse loss in hippocampal slice cultures (Nikonenko et al., 2003), whereas $\beta 1$ function-blocking peptides cause dendritic regression in retinal ganglion cells (Marrs et al., 2006). However, ablation of integrin $\beta 1$ in the mouse hippocampus does not affect hippocampal spine or dendrite structure, although it reduces synaptic transmission and plasticity (Chan et al., 2006; Huang et al., 2006). It is possible that other integrins compensate for the loss of integrin $\beta 1$. One candidate for this backup role would be integrin $\beta 3$, which localizes to hippocampal synapses (Chavis and Westbrook, 2001; Shi and Ethell, 2006) and can regulate the functional maturation of hippocampal synapses (Chavis and Westbrook, 2001). Future genetic studies should reveal whether these or other integrins act through Arg to regulate synapse development and dendritic maintenance in vivo.

\section{A model for integrin signaling through Arg and p190RhoGAP at synapses}

Our results strongly suggest that integrin signaling through Arg and p190RhoGAP acts at the synapse to regulate dendritic spine maturation and synapse/dendrite stability. We propose that this mechanism stabilizes synapses in a late stage of maturation. We hypothesize that synaptic activity promotes localized synthesis or presentation of an integrin ligand. This ligand would engage postsynaptic integrin receptor to activate Arg/p190RhoGAP sig- 
naling and attenuate Rho-driven cytoskeletal rearrangements to promote spine maintenance. The ligand could be an extracellular matrix molecule, such as fibronectin or laminin, synthesized by support cells adjacent to the synapse. Alternatively, the ligand could be an unconventional integrin ligand such as Semaphorin 7a, which interacts with integrins (Pasterkamp et al., 2003) and can activate Arg-signaling in neurons (Moresco et al., 2005). Less effectual synapses would have reduced levels of this ligand, resulting in reduced signaling through Arg and p190RhoGAP. The resulting increase in Rho signaling would block dendritic spine maturation and lead to synaptic failure. Future studies should reveal which receptors and ligands activate Arg/p190RhoGAP signaling during dendritic spine maturation in vivo.

\section{References}

Anderton BH, Callahan L, Coleman P, Davies P, Flood D, Jicha GA, Ohm T, Weaver C (1998) Dendritic changes in Alzheimer's disease and factors that may underlie these changes. Prog Neurobiol 55:595-609.

Bernard-Trifilo JA, Kramar EA, Torp R, Lin CY, Pineda EA, Lynch G, Gall CM (2005) Integrin signaling cascades are operational in adult hippocampal synapses and modulate NMDA receptor physiology. J Neurochem 93:834-849.

Bradley WD, Hernandez SE, Settleman J, Koleske AJ (2006) Integrin signaling through Arg activates p190RhoGAP by promoting its binding to p120RasGAP and recruitment to the membrane. Mol Biol Cell 17:4827-4836.

Broadbelt K, Byne W, Jones LB (2002) Evidence for a decrease in basilar dendrites of pyramidal cells in schizophrenic medial prefrontal cortex. Schizophr Res 58:75-81.

Burt AM (1980) Morphologic abnormalities in the postnatal differentiation of CAl pyramidal cells and granule cells in the hippocampal formation of the ataxic mouse. Anat Rec 196:61-69.

Chan CS, Weeber EJ, Kurup S, Sweatt JD, Davis RL (2003) Integrin requirement for hippocampal synaptic plasticity and spatial memory. J Neurosci 23:7107-7116.

Chan CS, Weeber EJ, Zong L, Fuchs E, Sweatt JD, Davis RL (2006) $\beta 1$ integrins are required for hippocampal AMPA receptor-dependent synaptic transmission, synaptic plasticity, and working memory. J Neurosci 26:223-232.

Chavis P, Westbrook G (2001) Integrins mediate functional pre- and postsynaptic maturation at a hippocampal synapse. Nature 411:317-321.

Da Silva JS, Medina M, Zuliani C, Di Nardo A, Witke W, Dotti CG (2003) RhoA/ROCK regulation of neuritogenesis via profilin IIa-mediated control of actin stability. J Cell Biol 162:1267-1279.

Einheber S, Schnapp LM, Salzer JL, Cappiello ZB, Milner TA (1996) Regional and ultrastructural distribution of the alpha 8 integrin subunit in developing and adult rat brain suggests a role in synaptic function. J Comp Neurol 370:105-134.

Elia LP, Yamamoto M, Zang K, Reichardt LF (2006) p120 catenin regulates dendritic spine and synapse development through Rho-family GTPases and cadherins. Neuron 51:43-56.

Feng G, Mellor RH, Bernstein M, Keller-Peck C, Nguyen QT, Wallace M, Nerbonne JM, Lichtman JW, Sanes JR (2000) Imaging neuronal subsets in transgenic mice expressing multiple spectral variants of GFP. Neuron 28:41-51.

Finn AJ, Feng G, Pendergast AM (2003) Postsynaptic requirement for Abl kinases in assembly of the neuromuscular junction. Nat Neurosci 6:717-723.

Glantz LA, Lewis DA (2000) Decreased dendritic spine density on prefrontal cortical pyramidal neurons in schizophrenia. Arch Gen Psychiatry 57:65-73.

Govek EE, Newey SE, Akerman CJ, Cross JR, Van der Veken L, Van Aelst L (2004) The X-linked mental retardation protein oligophrenin-1 is required for dendritic spine morphogenesis. Nat Neurosci 7:364-372.

Govek EE, Newey SE, Van Aelst L (2005) The role of the Rho GTPases in neuronal development. Genes Dev 19:1-49.

Gresack JE, Frick KM (2003) Male mice exhibit better spatial working and reference memory than females in a water-escape radial arm maze task. Brain Res 982:98-107.

Harris KM, Jensen FE, Tsao B (1992) Three-dimensional structure of den- dritic spines and synapses in rat hippocampus (CA1) at postnatal day 15 and adult ages: implications for the maturation of synaptic physiology and long-term potentiation. J Neurosci 12:2685-2705.

Hernandez SE, Settleman J, Koleske AJ (2004) Adhesion-dependent regulation of p190RhoGAP in the developing brain by the Abl-related gene tyrosine kinase. Curr Biol 14:691-696.

Hirose M, Ishizaki T, Watanabe N, Uehata M, Kranenburg O, Moolenaar WH, Matsumura F, Maekawa M, Bito H, Narumiya S (1998) Molecular dissection of the Rho-associated protein kinase (p160ROCK)-regulated neurite remodeling in neuroblastoma N1E-115 cells. J Cell Biol 141:1625-1636.

Huang Z, Shimazu K, Woo NH, Zang K, Muller U, Lu B, Reichardt LF (2006) Distinct roles of the $\beta 1$-class integrins at the developing and the mature hippocampal excitatory synapse. J Neurosci 26:11208-11219.

Jones SB, Lu HY, Lu Q (2004) Abl tyrosine kinase promotes dendrogenesis by inducing actin cytoskeletal rearrangements in cooperation with rho family small GTPases in hippocampal neurons. J Neurosci 24:8510-8521.

Kaufmann WE, Moser HW (2000) Dendritic anomalies in disorders associated with mental retardation. Cereb Cortex 10:981-991.

Koleske AJ, Gifford AM, Scott ML, Nee M, Bronson RT, Miczek KA, Baltimore D (1998) Essential roles for the Abl and Arg tyrosine kinases in neurulation. Neuron 21:1259-1272.

Kramar EA, Bernard JA, Gall CM, Lynch G (2003) Integrins modulate fast excitatory transmission at hippocampal synapses. J Biol Chem 278:10722-10730.

Lamprecht R, Farb CR, LeDoux JE (2002) Fear memory formation involves p190 RhoGAP and ROCK proteins through a GRB2-mediated complex. Neuron 36:727-738.

Lee T, Winter C, Marticke SS, Lee A, Luo L (2000) Essential roles of Drosophila RhoA in the regulation of neuroblast proliferation and dendritic but not axonal morphogenesis. Neuron 25:307-316.

Lewis JM, Baskaran R, Taagepera S, Schwartz MA, Wang JY (1996) Integrin regulation of c-Abl tyrosine kinase activity and cytoplasmic-nuclear transport. Proc Natl Acad Sci USA 93:15174-15179.

Li Z, Van Aelst L, Cline HT (2000) Rho GTPases regulate distinct aspects of dendritic arbor growth in Xenopus central neurons in vivo. Nat Neurosci 3:217-225.

Li Z, Aizenman CD, Cline HT (2002) Regulation of rho GTPases by crosstalk and neuronal activity in vivo. Neuron 33:741-750.

Lin B, Arai AC, Lynch G, Gall CM (2003) Integrins regulate NMDA receptor-mediated synaptic currents. J Neurophysiol 89:2874-2878.

Luo L (2002) Actin cytoskeleton regulation in neuronal morphogenesis and structural plasticity. Annu Rev Cell Dev Biol 18:601-635.

Marrs GS, Honda T, Fuller L, Thangavel R, Balsamo J, Lilien J, Dailey ME, Arregui C (2006) Dendritic arbors of developing retinal ganglion cells are stabilized by beta 1-integrins. Mol Cell Neurosci 32:230-241.

Moresco EM, Scheetz AJ, Bornmann WG, Koleske AJ, Fitzsimonds RM (2003) Abl family nonreceptor tyrosine kinases modulate short-term synaptic plasticity. J Neurophysiol 89:1678-1687.

Moresco EM, Donaldson S, Williamson A, Koleske AJ (2005) Integrinmediated dendrite branch maintenance requires Abelson (Abl) family kinases. J Neurosci 25:6105-6118.

Mueller BK, Mack H, Teusch N (2005) Rho kinase, a promising drug target for neurological disorders. Nat Rev Drug Discov 4:387-398.

Nakayama AY, Harms MB, Luo L (2000) Small GTPases Rac and Rho in the maintenance of dendritic spines and branches in hippocampal pyramidal neurons. J Neurosci 20:5329-5338.

Nikonenko I, Toni N, Moosmayer M, Shigeri Y, Muller D, Sargent Jones L (2003) Integrins are involved in synaptogenesis, cell spreading, and adhesion in the postnatal brain. Brain Res Dev Brain Res 140:185-194.

Nishimura SL, Boylen KP, Einheber S, Milner TA, Ramos DM, Pytela R (1998) Synaptic and glial localization of the integrin alphavbeta8 in mouse and rat brain. Brain Res 791:271-282.

Pasterkamp RJ, Peschon JJ, Spriggs MK, Kolodkin AL (2003) Semaphorin 7A promotes axon outgrowth through integrins and MAPKs. Nature 424:398-405.

Peacock JG, Miller AL, Bradley WD, Rodriguez O, Webb DJ, Koleske AJ (2007) The Abl-related gene (Arg) tyrosine kinase acts through p190RhoGAP to inhibit actomyosin contractility and regulate focal adhesion dynamics upon adhesion to fibronectin. Mol Biol Cell, in press.

Ramakers GJ (2000) Rho proteins and the cellular mechanisms of mental retardation. Am J Med Genet 94:367-371. 
Ridley AJ (2001) Rho GTPases and cell migration. J Cell Sci 114:2713-2722. Rodriguez MA, Pesold C, Liu WS, Kriho V, Guidotti A, Pappas GD, Costa E (2000) Colocalization of integrin receptors and reelin in dendritic spine postsynaptic densities of adult nonhuman primate cortex. Proc Natl Acad Sci USA 97:3550-3555.

Ruchhoeft ML, Ohnuma S, McNeill L, Holt CE, Harris WA (1999) The neuronal architecture of Xenopus retinal ganglion cells is sculpted by rhofamily GTPases in vivo. J Neurosci 19:8454-8463.

Santos Da Silva J, Schubert V, Dotti CG (2004) RhoA, Rac1, and cdc42 intracellular distribution shift during hippocampal neuron development. Mol Cell Neurosci 27:1-7.

Schikorski T, Stevens CF (1997) Quantitative ultrastructural analysis of hippocampal excitatory synapses. J Neurosci 17:5858-5867.

Schubert V, Da Silva JS, Dotti CG (2006) Localized recruitment and activation of RhoA underlies dendritic spine morphology in a glutamate receptor-dependent manner. J Cell Biol 172:453-467.

Shi Y, Ethell IM (2006) Integrins control dendritic spine plasticity in hippocampal neurons through NMDA receptor and $\mathrm{Ca} 2{ }^{+} /$calmodulindependent protein kinase II-mediated actin reorganization. J Neurosci 26:1813-1822.

Tashiro A, Minden A, Yuste R (2000) Regulation of dendritic spine morphology by the rho family of small GTPases: antagonistic roles of Rac and Rho. Cereb Cortex 10:927-938.
Thompson CL, Van Vactor D (2006) Abelson family protein tyrosine kinases and the formation of neuronal connectivity. In: Abl family kinases in development and disease (Koleske AJ, ed), pp 105-122. New York: Springer.

Thumkeo D, Keel J, Ishizaki T, Hirose M, Nonomura K, Oshima H, Oshima M, Taketo MM, Narumiya S (2003) Targeted disruption of the mouse rho-associated kinase 2 gene results in intrauterine growth retardation and fetal death. Mol Cell Biol 23:5043-5055.

Van Aelst L, Cline HT (2004) Rho GTPases and activity-dependent dendrite development. Curr Opin Neurobiol 14:297-304.

Wills Z, Bateman J, Korey CA, Comer A, Van Vactor D (1999) The tyrosine kinase $\mathrm{Abl}$ and its substrate enabled collaborate with the receptor phosphatase Dlar to control motor axon guidance. Neuron 22:301-312.

Woodring PJ, Litwack ED, O'Leary DD, Lucero GR, Wang JY, Hunter T (2002) Modulation of the F-actin cytoskeleton by c-Abl tyrosine kinase in cell spreading and neurite extension. J Cell Biol 156:879-892.

Zoghbi HY (2003) Postnatal neurodevelopmental disorders: meeting at the synapse? Science 302:826-830.

Zukerberg LR, Patrick GN, Nikolic M, Humbert S, Wu CL, Lanier LM, Gertler FB, Vidal M, Van Etten RA, Tsai LH (2000) Cables links Cdk5 and c-Abl and facilitates Cdk5 tyrosine phosphorylation, kinase upregulation, and neurite outgrowth. Neuron 26:633-646. 